\title{
ATRESIA OF THE OESOPHAGUS WITH COMMON TRACHEO-OESOPHAGEAL TUBE
}

\author{
BY
}

\author{
R. G. WELCH and O. A. N. HUSAIN \\ From the Paediatric and Pathology Departments, Lambeth Hospital, London
}

(RECEIVED FOR PUBLICATION JANUARY 3, 1958)

The clinical picture and anatomical variants of oesophageal atresia are well known now that this condition can be treated surgically with fair hope of success. In about $90 \%$ of cases there is a fistula connecting the lower segment of the oesophagus to the trachea and in some $9 \%$ the atresia is present alone without a fistula. Amongst the remainder there are instances where the fistula passes from the upper pouch to the trachea, where there is a fistula connecting each segment to the trachea and where a fistula occurs without any atresia (Waterston, 1954). In the case of the infant described here, however, though in life the findings did not appear out of the ordinary, autopsy revealed a most unusual malformation and it is perhaps fortunate that the child's general condition precluded any attempt at surgical correction.

\section{Case History}

A male child, birth weight $6 \mathrm{lb}$., was born rapidly at home five weeks before term. The pregnancy had been uneventful and he was the third child of healthy parents, the mother's age being 23 . Respiration could not be established and atresia of the oesophagus became apparent when a catheter could not be passed into the stomach. Intermittent gasping respiration followed mouth-to-mouth insufflation and the child was transferred to hospital where, following intra-tracheal oxygen, a more regular, but stertorous and rattling, respiration was established about two and a half hours after birth. The child remained limp and unresponsive, with intermittent cyanotic attacks and a low temperature. Numerous rales were audible all over the chest and the intestines filled with air. After some hours the intra-tracheal tube was removed but, as the child's condition and colour promptly deteriorated, it was reinserted, this time rather further than before. It was then noted that the condition remained poor until the tube was withdrawn a short way, but the significance of this was not appreciated until autopsy. After 36 hours, during which time the child never developed muscle tone or became responsive, the stertorous respirations became periodic and death followed at 48 hours.

At autopsy an oedematous and congested brain was found with blood clot around the circle of Willis and brain stem. No aneurysm or bleeding point could be identified. The right kidney and all its ureter, apart from a short distal portion, were absent. The heart was normal and there were no abnormal blood vessels apparent in the neck and chest. The oesophagus ended blindly as a pouch $1 \mathrm{~cm}$. below the laryngeal entrance.

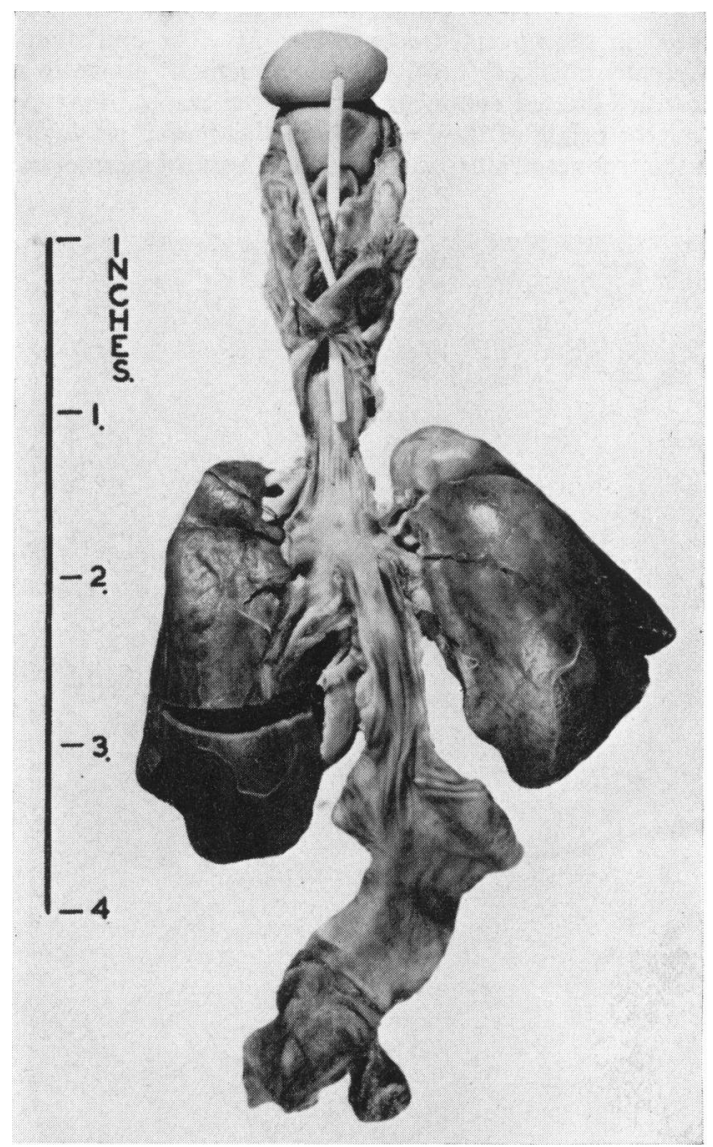

Fig. 1.-One marker lies under the oesophageal pouch and the other is passed through the larynx into the common tube. 
The larynx was normal and opened wholly into a tube which appeared to be an oesophagus, but at its upper end, below the thyroid cartilage, were a normal cricoid cartilage and three poorly formed tracheal rings, all hidden behind the thyroid gland. The tube, having given off the two main bronchi in mid-thorax, passed normally through the left side of the diaphragm and into the stomach (Fig. 1). The bronchi and lobes of the lung were anatomically normal with well-formed cartilagenous rings.

Microscopy disclosed that the upper oesophageal pouch was lined by stratified squamous epithelium. There were no mucous glands and the submucosa contained a scanty muscularis mucosa. The wall was of striated muscle fibres arranged normally in outer circular and inner longitudinal coats (Fig. 2). The wall of the common tracheo-oesophageal tube contained only unstriped muscle fibres, mainly in longitudinal bundles with less well-developed outer circular fibres. The mucous glands were scattered generally throughout the submucosa, both superficial and deep, to the scanty and illdefined muscularis mucosa, and also deep within the muscle coat. These glands had the appearance of those found in the normal trachea (Fig. 3). The epithelium gradually changed from stratified squamous above to a stratified cilated columnar form of the respiratory type near the origin of the bronchi and this passed gradually to the true respiratory mucosa in the bronchi themselves.

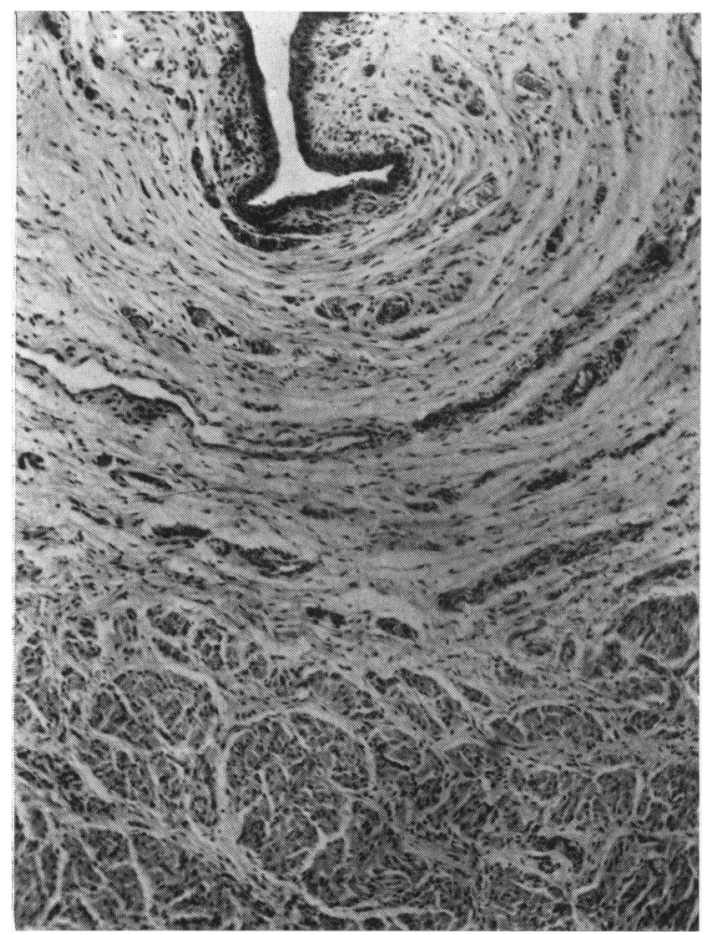

Fig. 2.-Section through wall of upper oesophageal pouch. $\quad \times 70$.
Some of the mucosal epithelium had been stripped off by a mild inflammatory reaction and trauma (probably by the intra-tracheal tube).

The lungs were surprisingly well aerated with some scattered intra-alveolar haemorrhages.

\section{Discussion}

The interest of this case lies not only in the most unusual gross findings at autopsy but also in the histological appearance of this common tracheooesophageal tube which, though lacking all but the first three cartilagenous rings, had in it mucous glands of the type normally found in the trachea., as well as epithelium of both sorts. There is, of course, a wide variety of congenital anomalies involving trachea and oesophagus ranging from complete absence of the oesophagus (Wilkins, 1938) on the one hand, through absence of a segment of oesophagus (usually in association with a tracheo-oesophageal fistula), tracheal stenosis and hypoplasia (Wolman, 1941), to complete absence of trachea on the other. For two structures so intimately related in their development, it is surprising that the atresias of the oesophagus should be so much the more common. Estimates of its frequency vary, but it is probably in

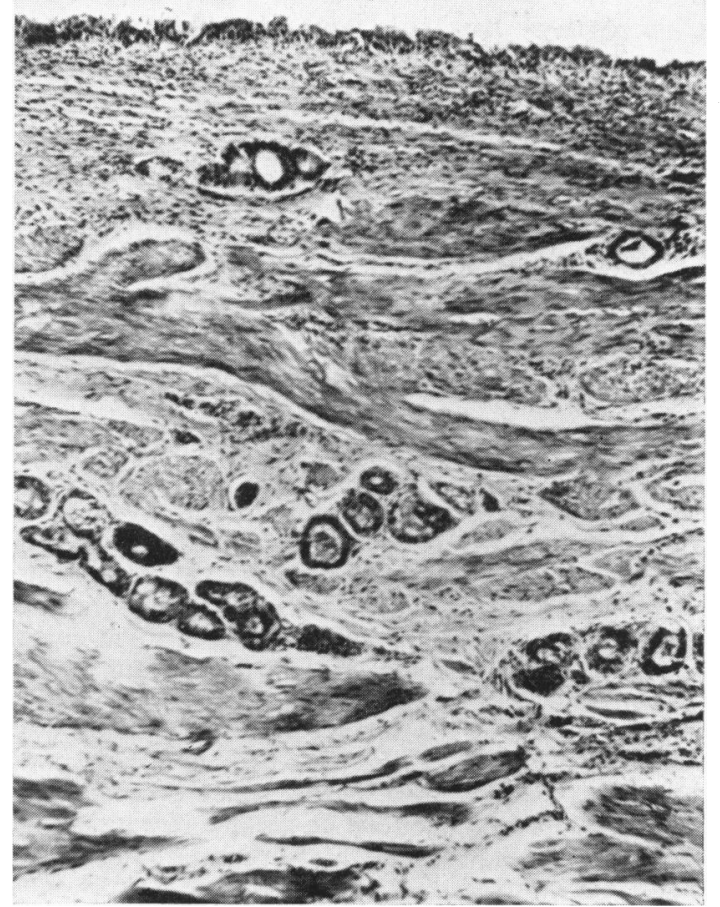

Fig. 3.-Section through wall of common tracheo-oesophageal tube, midway between larynx and bronchi. $\times 70$. 
the nature of 1 to every 1,500 births (Scott and Wilson, 1957). On the other hand, recorded examples of absence of the trachea are very rare. Fritz (1933) and Sandison (1955) have each reported a case where the bronchi opened normally into a short lower segment of trachea from the roof of which a fistula passed to a normal oesophagus. In the infants described by Kessel and Smith (1953) and Hempel (1956) the conjoined bronchi connected by a fistula to the oesophagus whilst in those recorded by Walcher (1928), Benešová and Peter (1934) and Marek (1940) the bronchi opened directly into the oesophagus. In Payne's case (1900) the main bronchi were connected to each other but to nowhere else, a state of affairs very similar to that described by Milles and Dorsey (1950). The continental authors mention a few similar cases in the earlier European literature, but the total numbers are few and in all the larynx is occluded by a sheet of cartilage or membrane with the oesophagus apparently otherwise normal, though without histological examination for the most part.

This wide range of abnormality indicates a developmental defect at a very early stage. Gruenwald (1940) has described the early stage of an oesophageal atresia and tracheo-oesophageal fistula in a $9 \mathrm{~mm}$. embryo ( 5 to 6 weeks' ovulation age) and Ingalls and Prindle (1949) mention earlier reports of the fully developed malformation in $18 \cdot 1$ and $19 \mathrm{~mm}$. embryos.

Normal Development. According to Frazer (1953) the first trace of the future respiratory system is apparent in the $2.9 \mathrm{~mm}$. embryo (ovulation age 26 days) as a sagittal slit in the posterior part of the floor of the primitive pharynx, just cephalad to the oesophagus. This pulmonary outgrowth appears externally as a keel-like projection which soon begins to extend caudally over the ventral surface of the oesophagus, the two lung buds appearing at its lower end. By the $4 \mathrm{~mm}$. stage the entodermal lung buds are projecting into a mesodermal mass continuous at its caudal end with the septum transversum which, being fixed, serves to anchor the lung buds in their subsequent development. Lateral ridges appear in the pulmonary outgrowth and fuse mesially in a caudo-cephalic direction at the same time as the oesophagus and pulmonary outgrowth are elongating rapidly, thus separating progressively the primitive main bronchi, trachea and infra-glottic part of the larynx from the oesophagus. When the pulmonary outgrowth first appears only the first two pharyngeal arches are apparent, but by the $5 \mathrm{~mm}$. stage ( 30 days) it has come to lie between the sixth arches, just behind the hypobranchial eminence.
The major (supraglottic) part of the larynx, down to and including the vocal cords and the cricoid, develops from the fourth and sixth arches and the hypobranchial eminence and is thus pharyngeal in origin, which perhaps explains why the larynx is more or less normal despite absence of the trachea beyond in the cases mentioned. In its early stages the narrow infraglottic cavity is compressed from side to side and is almost completely occluded for a short time by epithelial fusion, only small dorsal and ventral tracts leading to the patent part of the tracheal outgrowth. The larynx is well seen in the $16 \mathrm{~mm}$. embryo (about the seventh week). Early in its development the cells lining the oesophagus undergo intensive proliferation but vacuoles. become apparent at the end of the sixth week and, although occlusion occurs as a temporary phase in the crocodilia and reptiles (Reese, 1926), it is never complete in the human (Johns, 1952). Chondrification in the trachea becomes apparent at the $20 \mathrm{~mm}$. stage.

The associated absence of kidney also helps to date development of the abnormality as the ureteric bud appears at the end of the fifth week. Rosenthal (1931), Ladd (1944) and Sandison (1955) have also recorded instances where absence of kidney is associated with tracheo-oesophageal abnormalities.

Pathogenesis. Rosenthal (1931), amongst others, has reviewed the theories of pathogenesis of oesophageal atresia, and divides them into three main groups, those based firstly upon retardation of oesophageal development at a time when it is solid (subsequently shown to be a faulty premise), secondly upon deviations and malformations of the tracheo-oesophageal septum and thirdly upon the presumed effects of changes in tension on the developing embryo (as might be exerted by an overlarge cardiac anlage, excessive flexion of the embryo or the development of blood vessels in abnormal sites).

The defect seen in this case, however, appears to be far more fundamental with the persistence of a common tube. It can best be explained on the assumption that the lateral ridges have never appeared and the pulmonary outgrowth has thus never separated from the oesophagus. The lung buds have penetrated the mesenchyme in the usual manner and with the subsequent growth of the embryo, larynx and bronchi have become widely separated. The larynx, being pharyngeal in origin, has developed normally, as have the lung buds. The existence of the dorsal oesophageal pouch behind the larynx is explained by the fact that the upper portion of the oesophagus derives partly from the 
pharynx (it contains striped muscle in its wall). The posterior wall of the pharynx, at the level of the pulmonary outgrowth, has formed the pouch, perhaps after the fashion of a pulsion diverticulum. Associated with this defect is a lack of chondrification of the majority of the tracheal rings.

\section{Summary}

Details are presented of an infant in whom an oesophageal atresia was found in association with a common tracheo-oesophageal tube from which arose bronchi and stomach. The pathogenesis of this and similar conditions is discussed.

Our thanks are due to Dr. B. D. R. Wilson for per- mission to publish details of this child and to Dr. $\mathbf{H}$. Spencer and others for their help and advice.

\section{REFERENCES}

Beněová, D. and Peter, P. (1934). Č́as. Lék. čes., 73, 356.

Frazer, J. E. (1953). Manual of Embryology, 3rd ed. London.

Fritz, E. (1933). Virchows Arch. path. Anat., 289, 264.

Gruenwald, P. (1940). Anat. Rec., 78, 293.

Hempel, K. J. (1956). Zbl. allg. Path. path. Anat., 95, 226

Ingalls, T. H. and Prindle, R. A. (1949). New Engl.J.Med., 240, 987

Johns, B. A. E. (1952). J. Anat. (Lond.), 86, 431.

Kessel, I. and Smith, J. N. (1953). Thorax, 8, 266.

Ladd, W. E. (1944). New Engl.J. Med., 230, 625.

Marek, J. J. (1940). Ohio St. med. J., 36, 1308.

Milles, G. and Dorsey, D. B. (1950). Amer.J. Path., 26, 411.

Payne, W. A. (1900). Brooklyn med. J., 14, 568.

Reese, A (1926) Amer J. Anat $37,195$.

Rosenthal, A. H. (1931). Arch. Path. (Chicago), 12, 756.

Sandison, A. T. (1955). Arch. Dis. Childh., 30, 475 .

Sandison, A. T. (1955). Arch. Dis. Childh., 30, 475.

Scott, J. S. and Wilson, J. K. (1957). Lancet, 2, 569.

Waterston, D. J. (1954). In Recent Advances in Paediatrics (edited D. Gairdner), p. 151. London.

Wilkins, S. O. (1938). J. med. Soc. N.J., 35, 737.

Wolman, I. J. (1941). Amer. J. Dis. Child., 61, 1263. 